\title{
CFD ANALYSIS OF THE EFFECT OF MACH NUMBER ON
}

\section{SCRAMJET COMBUSTION}

\section{G. SANTHANAM ${ }^{1}$, C. SRINIVAS ${ }^{2}$, CH. KHYATHI SREE $^{3}$ \& S. SRINIVAS PRASAD ${ }^{4}$}

${ }^{1}$ Associate Professor, Department of Mechanical Engineering, PSCMR College of

Engineering Technology, Vijayawada, Andhra Pradesh, India

${ }^{2}$ Associate Professor, Department of Mechanical Engineering, RVR and JC College of

Engineering, Guntur, Andhra Pradesh, India

${ }^{3}$ P. G Scholar, Department of Mechanical Engineering, V. R Siddhartha Engineering College,

Vijayawada, Andhra Pradesh, India

${ }^{4}$ Professor, Department of Mechanical Engineering, V. R Siddhartha Engineering College,

Vijayawada, Andhra Pradesh, India

\begin{abstract}
Understanding the scramjet combustion and significant effect of each parameter is very much important for the design and analysis. The computational analysis has been carried out by using the commercial software FLUENT. The 3D, Steady, Compressible reacting flow has been simulated using k-epsilon turbulence model, species transport combustion model and finite rateleddy dissipation model for reacting flow. The scramjet combustor selected is same as the combustor at DLR institute for space propulsion. The $\mathrm{H} 2$ fuel is injected through the strut at its center. The operating conditions used for the engine are Mach number 2, and the mass flow rate of the hydrogen from the injector is 0.004 $\mathrm{kg} / \mathrm{s}$. The computational results obtained from the analysis have been validated and the effect of Mach number has been systematically studied with the help of static pressure and static temperature in the combustor. The physics of the flow field in combustor such as mixing, atomization, combustion has been captured by Mach, temperature and pressure contours.
\end{abstract}

KEYWORDS: Supersonic Combustion, K- $\varepsilon$ Turbulence Model, CFD Analysis, Reacting Flow, Non-Reacting Flow \& Mach Number

Received: Apr 19, 2019; Accepted: May 09, 2019; Published: Jun 29, 2019; Paper Id.: IJMPERDAUG201939

\section{INTRODUCTION}

The development of the hypersonic air-breathing propulsion system has long been a target of the aerospace community. The principle method of hypersonic air-breathing propulsion is the scramjet Engine, which is also called as the supersonic combustion ramjet engine, where the combustion takes place at very high speeds. The atmospheric air entering the inlet section at high velocities gets reduced as it passes through the diffuser, which results in the increase of static pressure and temperature when passing through the narrow cross-section of the combustion chamber. Scramjet engines depend on the combustion of fuel and oxidizer to produce thrust. The scramjet has three basic components. Firstly, the air is compressed in the converging inlet, and the heat is produced when the gaseous fuel is burnt with the atmospheric air within the combustor, and the heated air is accelerated to produce thrust within the diverging nozzle. The combustion takes place at supersonic velocities with 
the help of atmospheric oxygen and hydrogen as the propellant, the exhaust gas being steam $\left(\mathrm{H}_{2} \mathrm{O}\right)$ which is eco-friendly in nature. Computational Fluid Dynamics (CFD) is a computational tool, particularly developed to solve the complex problems of fluid dynamics. CFD plays several roles serving as an engineering tool for the detailed design and analysis of hypersonic propulsion system.

K. M. Pandey et. al, [1] worked on the topic of "CFD Analysis of a Hydrogen Fueled Mixture in Scramjet Combustor with a Strut Injector by Using Fluent Software". They investigated hydrogen injection with supersonic cold flow. K. M. Pandey et. al, [2] worked on the "Recent Advances in Scramjet Fuel Injection - A Review", and they concluded that the air and fuel should be mixed to stoichiometric properties to achieve efficient combustion. Also, the air flow is very fast allowing very less time to mix with the fuel to produce thrust. Malsur Dharavath et. al, [3] presented "Numerical exploration of non-reacting and reacting flow field of hydrogen fueled scramjet combustor", they concluded that 3D RANS equations are solved along with $\mathrm{K}-\varepsilon$ turbulence model, by injecting hydrogen into the fluid domain and the air flowing at Mach 2 simulations are performed in fluent. K. Kumaran et. al, [4] concluded that compared to single step chemistry, the Multi step chemistry is predicting wider and higher spread heat release. The whole performance constraints with less computational time are predicted well by the use of single step chemistry. Sankaran et. al, [5] investigated the mechanism of flame holding in the supersonic flow of a planer strut, the standard k-epsilon turbulence model is used for simulating the flow field of the $\mathrm{H}_{2}$ fueled scramjet combustor under two working conditions, namely engine ignition and cold flow. Gruenig et. al, [6] worked on the topic of "Supersonic combustion of kerosene/h2-mixtures in a model Scramjet combustor", and concluded that the required temperature level is achieved with increasing combustor area ratio. Chandra PrakashTourani [7] worked on "Computational simulation of scramjet combustors-A comparison between quasi 1-D and 2D numerical simulations". He performed 1-D simulations based on the quasi 1-D equations of fluid motion and 2-D simulations based on RANS equations for NASA's SCHOLAR and DLR supersonic combustors. Shigeru Aso et. al [8] worked on "Fundamental study of supersonic combustion in air flow with use of shock tunnel", they concluded that increase in pressure of injection caused strong bow jerk, resulting in less pressure. Shock generator is an effective way to speed up combustion. Engman [9] carried out the work on hydrogen combustion in scramjet engine at the of German Aerospace center, DLR in cologne, Germany. Engman validated his experimental results with CFD simulation and blue flame simulation and found good agreement. Peter Hyslop [10] used CFD-ACE to model the flow inside ANU's experimental Scramjet Engine. In this work, CFD-ACE is verified with previous work, and experimental verification of optimal configuration. Calculation of thrust, pressure forces and shear forces are all done. Animhons et. al [11] worked on "Numerical simulation of SCRAMJET engine". In this context, he investigated the flow field and analyzed the graphical results obtained using Fluent. Here, the computation is carried out to solve the flow field variable.

\section{PHYSICAL MODEL AND OPERATING CONDITIONS}

\subsection{Physical Model}

The Scramjet combustion chamber used at the Institute for chemical propulsion of German Aerospace Center, DLR by Waidmann et $\mathrm{al}^{12}$, has been chosen for study. A schematic scramjet combustor, similar to the experimental setup is presented in Figure. 1. 


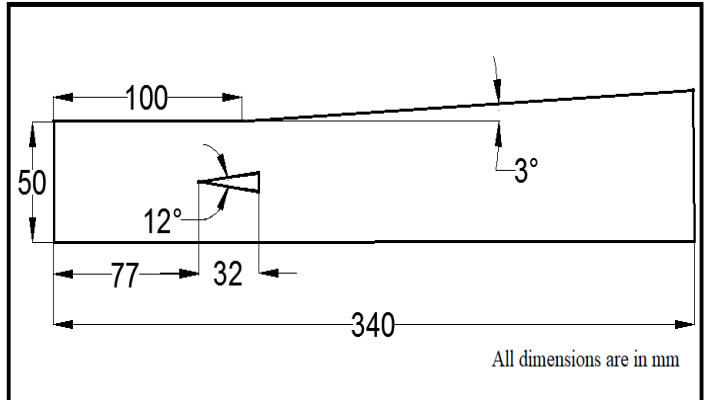

Figure 1: Schematic of DLR Combustion Chamber

The total width of the combustion chamber is $40 \mathrm{~mm}$. The height is $50 \mathrm{~mm}$ at the inlet. The air enters through the inlet, hydrogen is injected parallel to the stream of air through 15 holes, each having a diameter of $1 \mathrm{~mm}$. The upper combustible wall has a 3-degree divergence angle to prevent the thermal choking of the vessel due to the heat released by combustion. Planer fuel injection area used in the computational analysis has been considered similar to the fuel injection area used at DLR.

\subsection{Operating Conditions}

The species specifications and the different operating conditions like pressure, temperature and density selected for the analysis are listed below. This data is taken from K M Pandey ${ }^{1}$.

Table 1: Inflow Conditions of the Air Stream and the Hydrogen Jet

\begin{tabular}{|l|c|c|}
\hline \multicolumn{1}{|c|}{ Parameters } & Air & Hydrogen \\
\hline Mach number & 2 & 1 \\
\hline Static temperature $(\mathrm{K})$ & 340 & 250 \\
\hline Static pressure $(\mathrm{bar})$ & 1 & 1 \\
\hline Axial velocity $(\mathrm{m} / \mathrm{sec})$ & 730 & 1200 \\
\hline Density $\left(\mathrm{kg} / \mathrm{m}^{3}\right)$ & 1.002 & 0.097 \\
\hline $\mathrm{O}_{2}$ mass fraction & 0.232 & 0 \\
\hline $\mathrm{H}_{2}$ Omass fraction & 0.032 & 0 \\
\hline $\mathrm{N}_{2}$ mass fraction & 0.736 & 0 \\
\hline $\mathrm{H}_{2}$ mass fraction & 0 & 1 \\
\hline Mass flow rate $(\mathrm{kg} / \mathrm{sec})$ & 1.5 & 0.0015 to 0.004 \\
\hline Kinetic energy $(\mathrm{m} / \mathrm{sec})$ & 10 & 2400 \\
\hline Eddy dissipation $(\mathrm{m} / \mathrm{sec})$ & 650 & $1 \mathrm{e} 8$ \\
\hline
\end{tabular}

\section{COMPUTATIONAL METHODOLOGY}

\subsection{Geometry and Mesh used in the Analysis}

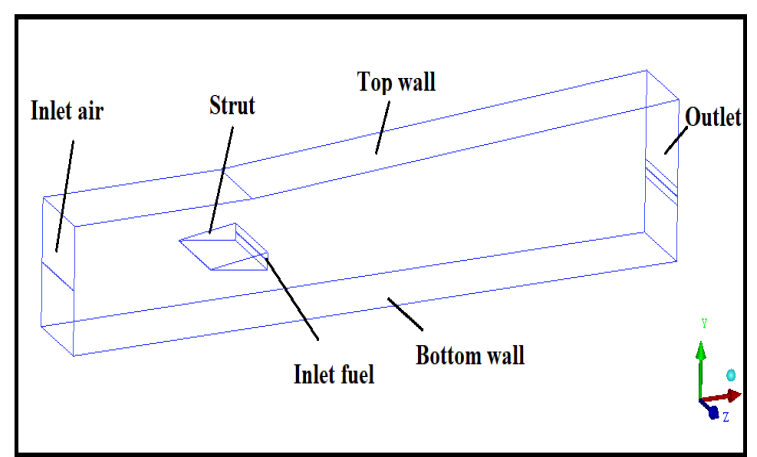

Figure 2: 3D Modeling of DLR Scramjet Combustor 
The geometry of scramjet engine duct and strut are created using ICEM CFD. HEXA mesh has been created in the computational domain by the use of blocking strategy. The total number of hexahedral elements used is 30,000 , as shown in Figure. 3. The fuel injection is changed from circular to planar to reduce the geometry complexity and the fuel injection area is same as used at DLR experimental setup, is shown in Figure. 4.

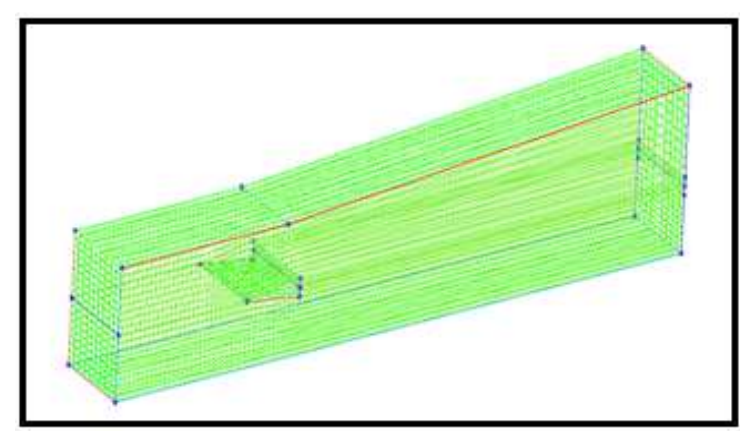

Figure 3: Discretization of the Fluid Domain

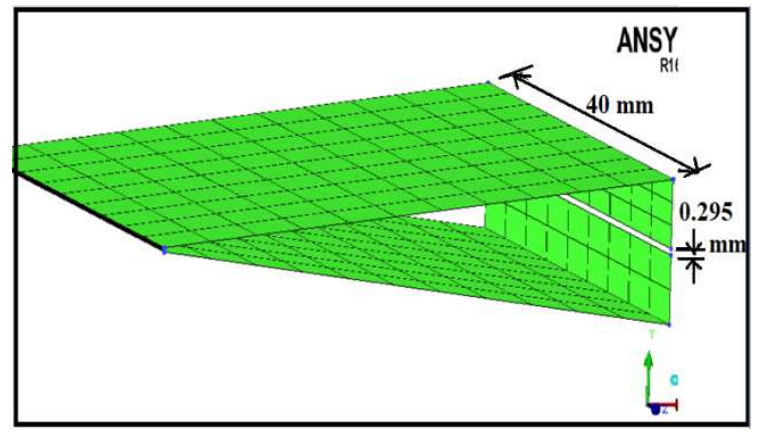

Figure 4: Mesh Generation over the Strut

\subsection{Boundary Conditions}

The necessary boundary conditions are given below.

Table 2: Boundary Conditions

\begin{tabular}{|l|l|}
\hline \multicolumn{1}{|c|}{ Model/Setup } & \multicolumn{1}{c|}{ Conditions Used } \\
\hline Solver type & Pressure based solver \\
\hline Viscous model & K-epsilon \\
\hline Mixture material & Hydrogen-air \\
\hline Turbulence-Chemistry interaction & Eddy-Dissipation model \\
\hline Air & Ideal gas \\
\hline Specific heat & Piecewise-polynomial \\
\hline Viscosity & Sutherland \\
\hline Inlet air & Pressure far field/ Mach Number \\
\hline Inlet fuel & Mass flow inlet \\
\hline Wall & No slip \\
\hline Monitors & $1 \mathrm{e}-3$ \\
\hline Under relaxation factors & Default \\
\hline
\end{tabular}

\section{RESULTS AND DISCUSSIONS}

The numerical simulation of scramjet combustion has been done in ANSYS fluent solvent and the results obtained are presented, systematically. 


\subsection{Cold Flow Simulation}

In cold flow simulation, only the airflows along the fluid domain. The contours for Mach number, Static pressure and static temperature are shown in Figure 5, Figure 6 and Figure 7, for cold flow or fuel off simulation.

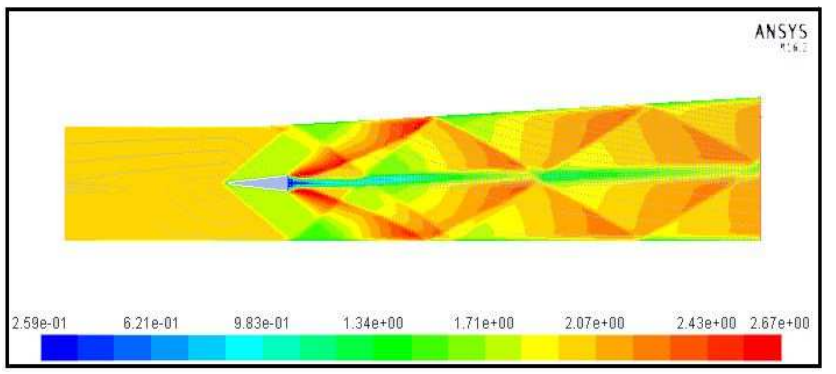

Figure 5: Mach Number Contours for Cold Flow Simulation

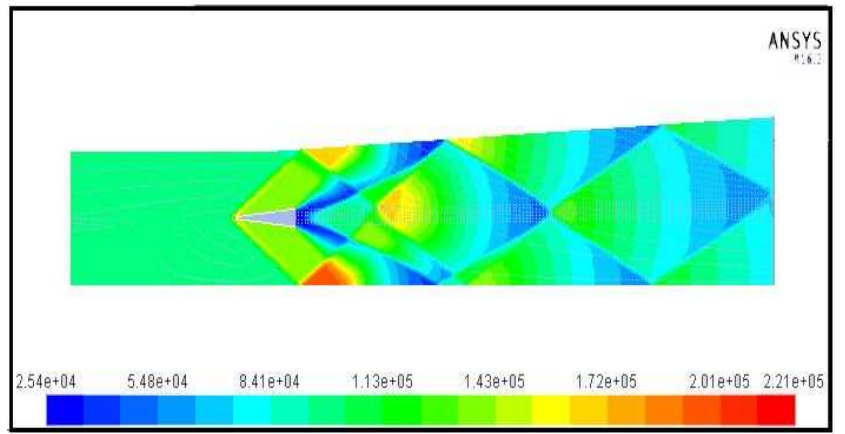

Figure 6: Static Pressure Contours for Cold Flow Simulation

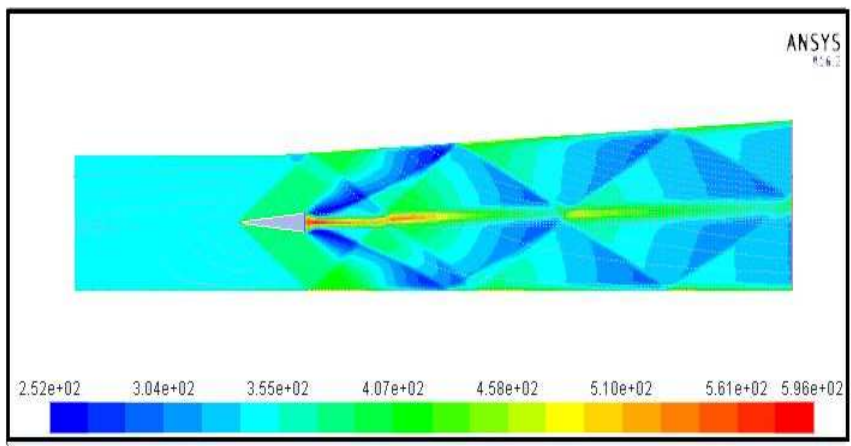

Figure 7: Static Temperature Contours for Cold Flow Simulation

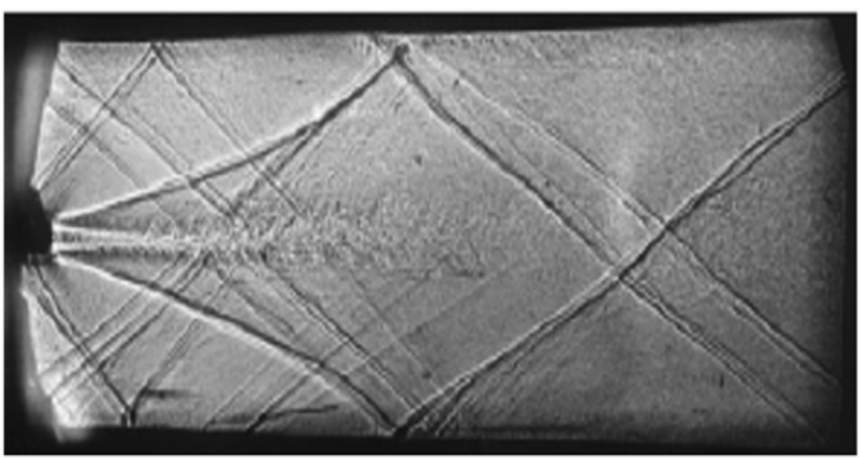

Figure 8: Experimental Shadow Graph [12] 
The expansion fans from the base of the strut, the complex shock structures from the leading edge and their reflections from the walls are clearly captured in the cold flow simulation, as shown in Figure.5.

The complex flow pattern in the wake region of the strut is seen in the pressure distribution presented in Figure. 6.

Experimental shadow graphs are shown and compared with the computational results to determine the position of shocks and their interactions.

\subsection{Reacting Case Simulation}

In reacting case simulation, the Hydrogen and air flows along the fluid domain. The contours for Mach number, Static pressure and static temperature are shown in Figure 9, Figure 10 and Figure 11, for reacting case simulation. Single step reaction considering $\mathrm{H}_{2}$ and $\mathrm{O}_{2}$ as reactants and $\mathrm{H}_{2} \mathrm{O}$ as product is considered for the present simulation.

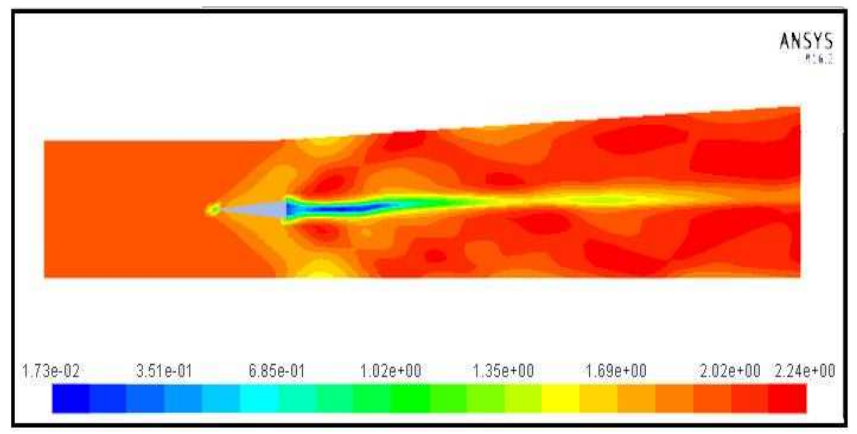

Figure 9: Mach Number Contours for Reacting Case Simulation

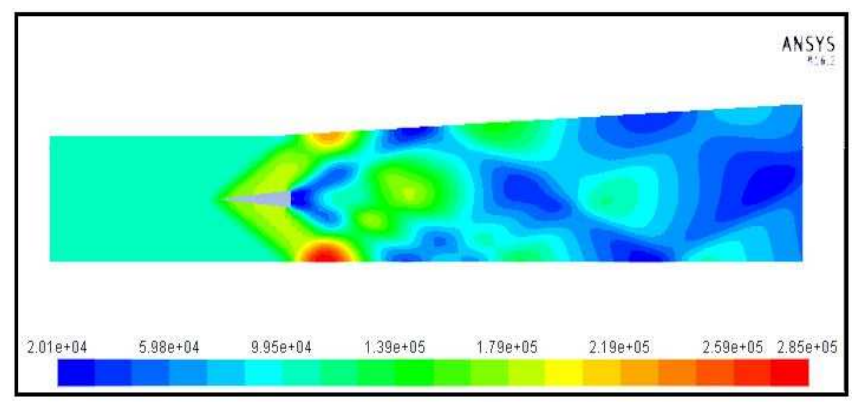

Figure 10: Static Pressure Contours for Reacting Case Simulation

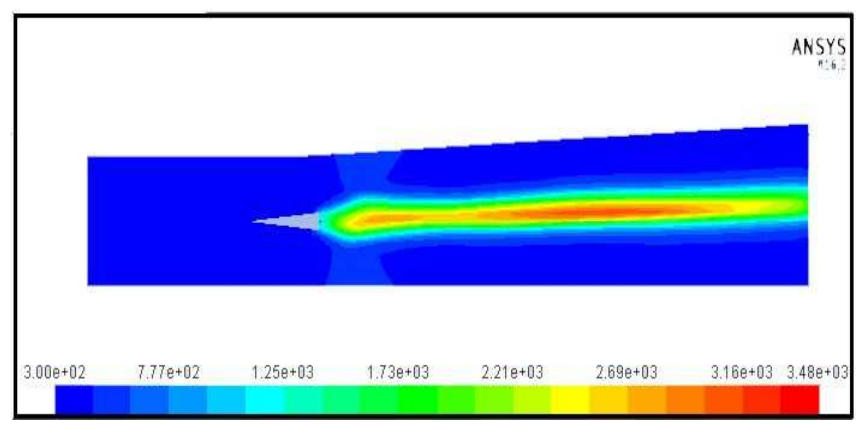

Figure 11: Static Temperature Contours for Reacting Case Simulation

Due to the presence of combustion, the recurrence area behind the wedge becomes larger than the one in the cold flow case. This enlarged rearrangement area acts as a flame holder for hydrogen diffusion flame. It is observed that the combustion effects the flow field, significantly. Both the near wall zones remain unaffected even after the combustion is 
completed, mainly because the injection is parallel and also because of the low fuel mass flow rate $(\mathrm{m}=0.004 \mathrm{~kg} / \mathrm{s})$.

\subsection{Validation}

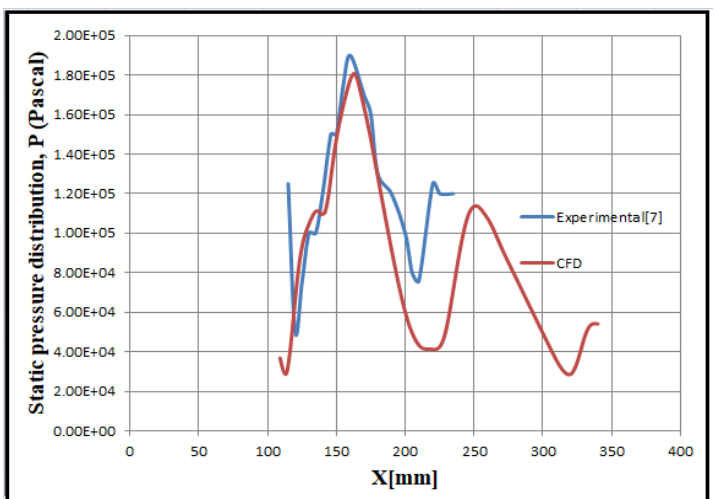

Figure 12: Static Pressure Distribution along the Centerline

The computed static pressure distribution along the centerline of the combustion chamber is compared with the experimental result, as shown in Figure. 12. The overall match is good. Both the magnitude and location of the pressure rise are correctly matched with experimental result.

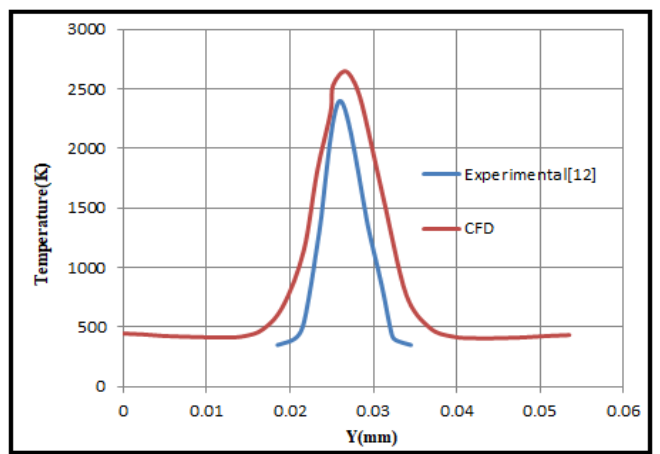

Figure 13: Static Temperature Distribution at $X=167 \mathrm{~mm}$

The computed temperature profiles at the axial location $(X=167 \mathrm{~mm})$ are compared with experimental result as shown in Figure. 13. The computed value of temperature distribution in the reaction zone is very close to experimental data. A small rise in temperature for CFD simulation is due to the instantaneous heat, released due to fast chemistry assumption.

\subsection{Effect of Mach Number}

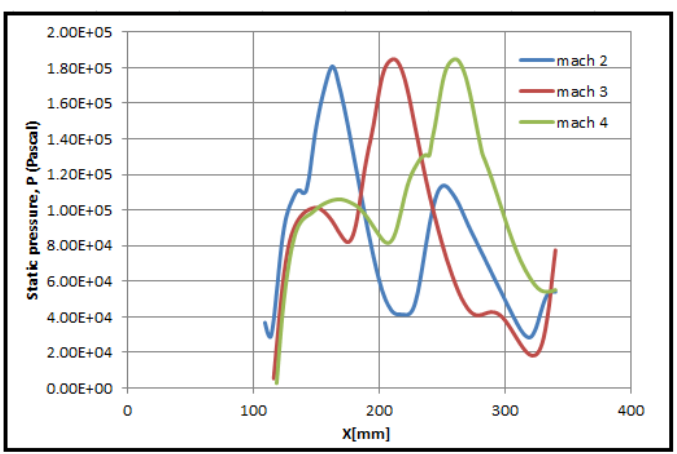

Figure 14: Static Pressure Distribution along the Centerline 


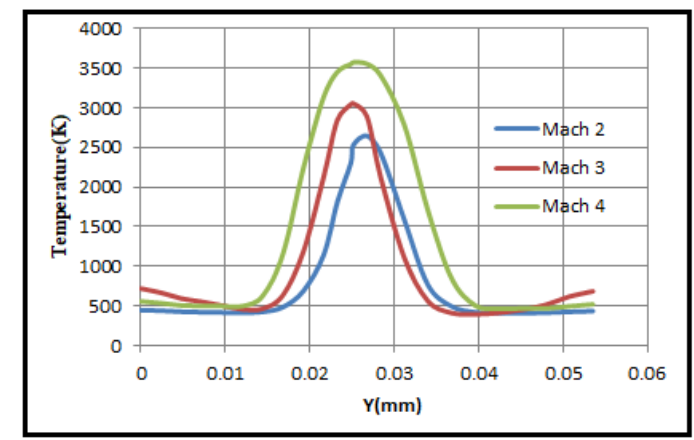

\section{Figure 15: Static Temperature Distribution at $X=167 \mathrm{~mm}$}

By increasing the Mach number, the maximum static pressure along the center line of the combustion is almost same, but the maximum peak static pressure is moving towards the downstream of the combustion chamber, as shown in Figure. 14. This is because, as Mach number increases, the velocity of incoming air increases and leads to fast chemistry reaction.

As Mach number increases the mass flow rate of air increases, therefore more air is supplied for combustion. It is presented in the Figure. 15, as Mach number increases, the temperature within the combustion chamber increases and is highest at the centerline of the combustion chamber. With current capabilities, the hydrogen-fueled scramjet will offer acceptable performance up to Mach 15.

\section{CONCLUSIONS}

The combustion phenomenon has been studied using fluent. The computational results are validated by comparing with the previously published experimental results. The compressible fluid flow effects such as oblique shockwave, reflected shock, the mixing and reacting flow has been successfully simulated. The effect of Mach number is systematically studied by varying with static pressure and static temperature plots.

\section{REFERENCES}

1. K M Pandey and T. sivasakthivel. "CFD Analysis of a Fueled Mixed in scramjet combustor with a strut injector by using Fluent software” International journal of engineering and technology vol. 3, no. 2, pp.109-115, 2011.

2. K. M. Pandey and T. Sivasakthivel, "Recent Advances in Scramjet Fuel Injection - A Review," International Journal of Chemical Engineering and Applications vol. 1, no. 4, pp. 294-301, 2010.

3. Malsur Dharavath, P. Manna, DebasisChakraborty "Thermochemical exploration of hydrogen combustion in generic scramjet Combustor", Computational Combustion Dynamics Division, Directorate of Computational Dynamics, Defence Research \& Development Laboratory, P. O. - Kanchanbagh, Hyderabad, India.

4. K. Kumaran and V. Babu, "Investigation of the effect of chemistry models on the numerical predictions of the supersonic combustion of hydrogen”, Combustion and Flame, vol 156, 2009, pp.826-841.

5. C. Gruenig and f. Mayinger, "supersonic combustion of kerosene/h2-mixtures in a model scramjet combustor", institute for thermodynamics, technical university Munich, and d-85747.

6. Chandraprakash Tourani "Computational simulation of scramjet combustors-" $A$ comparison between quasi-1D and $2 D$ numerical simulations" 
7. Shigeru Aso, Arif Nur Hakim, Shingo Miyamoto, Kei Inoue and Yasuhiro Tani, "Fundamental study of supersonic combustion in pure air flow with use of shock tunnel", Department of Aeronautics and Astronautics, Kyushu University, Japan, ActaAstronautica, vol 57, 2005, pp.384-389

8. Emil Engman, “Numerical Simulation of Scramjet Combustion”.

9. Peter Hyslop “CFD Modelling Of Supersonic Combustion In A Scramjet Engine”, Department Of Engineering Australian National University, 1998.

10. Swaminathan, C., \& Sarangan, J. (2012). Performance and exhaust emission characteristics of a CI engine fueled with biodiesel (fish oil) with DEE as additive. biomass and bioenergy, 39, 168-174.

11. A. Animhons, D. Nirmalkumar, A. Johnsree, “Numerical Simulation of Scramjet Engine “ International Journal of Engineering Research and General Science Volume 3, Issue 6, November-December, 2015, ISSN 2091-2730

12. Waidmann W., Alff F., Brummund U., Böhm M., Clauss W., Oschwald M.: 1995, "Supersonic Combustion of Hydrogen/Air in a Scramjet Combustion Chamber", Space Technology 15, p 421.

13. W. Waidmann, F. Alff, M. Bohm, U. Brummund, W. Clauss, M. Oschwald, "Experimental investigation of hydrogen combustion process in a Supersonic Combustion Ramjet (SCRAMJET)”, DGLR Jahrbuch, pp. 629-638, 1994. 
